\title{
Rodney Pybus on Jeffrey Wainwright
}

Jeffrey Wainwright has aimed high-a persona poem centred on a radical Christian in 16th-century Germany-but I think the form in this instance has been valuable, the first-person intensifying the sense of personal grappling with historical forces and the torments of faith and violence. And the attempt has been justified by an impressive and very accomplished poem. This is not history used for its own sake, but a means of widening and deepening the resonance of a (possibly) very narrow subject-Müntzer himself-and at the same time providing a sharply-detailed and sensuous focus for a wide-ranging theme, the translation of belief into action, and its consequences. I seem to detect a nod in Geoffrey Hill's direction in this poem ( some of the "Funeral Music" poems and "Endurance of Poets" sequence in King $\log$ ); if so, I can only say that it is well-directed, but not at all overdone.

Knowing that Jeffrey Wainwright has to reply to my comments, I want to say how I read the poem, rather than waste space in much general discussion, and to ask some questions, though necessarily in a more "shorthand" way than I feel does justice to the poem.

The first canto seeks to establish Müntzer's religious-visionary authority: his belief that he can walk on air and fly across water. But I get the impression of a degree of arrogance, intended or not, a whiff of hubris on Müntzer's part, not only in his seeming to outdo Christ's walking on the waters, but also in the implication in the last line and a half that he has found it a surprisingly easy feat. And as with all syndromes of hubris, the flights of arrogance must, Icarus-like, be succeeded by a fall, or, in a Christian context, a repetition of the Fall; perhaps the crucifixion pose is intended to set up in the reader's mind the expectation of defeat or self-sacrifice. Müntzer, to judge from his own words in the poem's first epigraph, seems to believe that since the Saviour is "supporting" him, he can advance not just on but above the water, "the movement to good and evil," avoiding the treacherous and sterile state of being "between life and death."

The movement of the first three stanzas is nicely judged-“above" in the first line sets up a verbal motion continued by "down" and "over," through the air to land again, the important elements picked out by the emphasis of the final words in each line of the third stanza-water, quick, air. What I am dubious about is whether we are actually intended to recognise this early in the poem a degree of religious pride which is to be followed by a fall. Further, the use of the second epigraph, from Machado, raises the question of how much credence we are to give to Müntzer's miraculous performances-are they to be taken as sheer self-delusion given substance by solitude and isolation? It's an important point, I think, and underlined by the particularity-the "one, two drops of water / On my beard." 
There is a careful emphasis too in the second canto on the fact that his brother's search for snail shells is not a vision: I take it that "brother" means "fellow human being" as well as the literal fraternal relationship. He is entangled at the most lowly level with the roots of social hierarchy and power, the "system," ranging up from the gardeners and journeymen who help to nourish and sustain it, to kings and emperor. This is a powerful image of the Tree of Power, intimately related to the Tree of Life, but in a perverted form. Müntzer sees these potentates and their maintenance as the fruits of an earth (in canto 3) that has turned against him: nothing fruitful for the likes of him. This is a very densely packed canto, and I'm not convinced that it works successfully: Müntzer struggles to subdue the earth, not, one notices, to cooperate with it, but to catch and possess-"she is mine," presumably sexually on one level, since "spread like a coat" suggests the urge to "cover" in the sense of impregnation; perhaps too, to "catch" at a propitious moment for that. Müntzer "forces" the earth successfully to become fruitful for him-the rowan blooms, from the previously recalcitrant earth. The flourishing mountain ash suggests not only the crucifixion "Tree," with its bleeding redemptive fruit, but the militant urge of Müntzer's religious beliefs, through the rowan's ancient military connotations. But are we to take the direction of these three stanzas as an inspiring, but eventually misleading, projection into the future (from Müntzer's point of view), or victory over a temporary period of sterility, or both? How are we to take the contrast with the tree in the previous canto? Images of, respectively, decadent corruption and fruitful regeneration juxtaposed to point up their differences? And is it the power of the tree subduing the barren earth or Müntzer's knowledge that he himself can achieve this regeneration which is the "power" referred to in the next canto, that books and scholars could not provide? (Again "power" suggests knowledge as possession, and an element of physical dominion.) I find this area of the poem difficult, open to various interpretations, not all of which seem mutually compatible, though many of the local effects are rich and suggestive; I liked the way, for instance, the idea of Müntzer as "a flier" in the first canto was picked up again at the start of canto 4 , and the way in which the alliance between scholarship and power was established in that canto.

The sarcastic, bitter tone of canto 5 signifies the change in language, and change in movement of the poem, all admirably managed, from the earlier complexity to the direct address: the irony becomes more brutal as Müntzer's demagogic attempts to rouse his sympathisers simplify the rhetoric without abandoning subtlety: they are not to have mercy though $w e$ are in a position to show it, and we know better than they what mercy is, since we have been without it from them for so long. In the next canto Müntzer seems to be caught in a Christian trap or dilemma: he knows what God's 
will is: God, he believes, will justify violence in His name, and blood shed by His enemies will purify the earth-although by the shedding of His Son's blood God made all men free, free as Himself, and finally, all men are Gods. Müntzer is unaware of any contradictions in his position, but it is arguable that at this particular moment his convictions needed to be so strong that self-questioning could not be admitted. I did not understand why he is "a true phantasist"-one who has fantasies, merely? Or are we to take it with echoes of "one who is fantastic" or "a creature of fantasy" or "a person with fantastic ideas" (fantast), or even "one who believes that Christ's body was a phantom" (phantasiast)?

The second half of the poem, as Müntzer grows in self-knowledge and awareness as his own position worsens, is more wholly successful for me than the first half. The language is more careful, precise and telling while no less imaginative, the movement and modulation of Müntzer's fortunes and states of mind, amplified in the tonal variations in the writing, are sustained without obscurity or emotional false notes. I have room here to note only one or two instances of how Jeffrey Wainwright achieves some of his most effective passages in the poem. In the linking repetition of "white" at the end of canto 9 and the start of canto 10, Müntzer is seen to be not only frightened and drained of blood but wearing his knowledge as suffering like his son's salt-white baptismal dress of wisdom, purified by the very process which is leading to physical defeat. Similarly in canto 11 with "bound": mercy is not mercy pure and simple-in this situation of conflict every gesture has strings attached. If the old woman is bandaged she will be "bound" to the enemy as well as by them; if she refuses attention, she will be "bound" to die.

In the final canto Müntzer's moment of truth is a sensitive and emotionally "accurate" piece of writing. He subjects the natural human desire for life to History, whose inevitable forces are given divine power by equation with "Eternal Life." He has tried to sacrifice his own mortality, evoked in the terrifying image of "rendering" his own flesh pure, like human flesh and fat being melted and "purified." History needs its sacrifices and celebrations, and in that lies spiritual, and presumably political, progress.

What I don't think the poem quite comes to terms with at the end are the implications of the last stanza: are we to assume from it that Müntzer's God has been subsumed by some quasi-Hegelian or Marxist historical forces, or that Müntzer is saying only that he has by self-sacrifice played a part in God's plans which will be executed through human history? Has religion been used as a justification for arguing that man must do more than keep pace with the advancement of History through "progress," if need be with violence that will be ultimately self-destructive? There seems to be some confusion here (perhaps only in my mind), that reflects back 
through the poem, between a religious and a secular version of, to put it crudely, "the end justifies the means"; and I am not sure whether Müntzer has become aware of this in a final, sad moment of understanding.

It will be clear that I have not found this poem easy to get to grips with -there's no reason why it should be. But I do think that what is potentially a very good poem is weakened in places by over-compression, and passages of opacity at crucial points. Having said that, I nevertheless reckon it is much the best poem of Jeffrey Wainwright's that I have read: more imaginatively aware, and as resourceful as ever.

\section{Jeffrey Wainwright Replies}

I am flattered and a good deal relieved that Rodney Pybus finds so much of what I am trying to do in "Thomas Müntzer." I think his reservations largely justified, and I have one major one to add, but first I want to try to respond to the questions he raises.

The recurring problem with Müntzer as I have presented him revolves around how much to believe him, believe in him, and how much he believes himself. $\mathrm{He}$ is precisely certain about his ability to fly ("one, two drops of water"), but obviously we, beginning as modern rationalists, will be sceptical, and anticipate disaster. But the simple freedom he describes, despite his tenseness, should also lead us to exult with him. However, for all its strength Müntzer too is forced to doubt his own vision at least in so far as he recognises his brothers' lives of toil beneath the Tree of Power as an unambiguous reality. But by its very intensity that recognition comes to be expressed in terms of great personal obsession, as a battle with the earth itself, a peasant battle but one also of scarcely sublimated sexuality. His new power comes almost as a sexual release brought both by his own devotion and effort and by divine help signalled by the fruit of the rowan -at once an amulet against evil and a version of the crucifixion. So his access to a sense of new power is a release from the sterility and frustration of his whole learned life so far and a gathering of energy for social action. It is to be, in Engels' phrase about Müntzer, a "terrorist energy." He is now delighted by his place in the establishment demonology, and especially by the description (Luther's) of him as "a true phantasist," for he does have fantastic ideas, is fantastic and beyond the imagination of his enemies, but he is also true and real, and so are his fantasies. Meaning dismissal, Luther confirms Müntzer's own view of himself.

And yet, as he sees himself, this massive self-image co-exists with the simple modest heart of his vision: an harmonious cooperative earthly paradise. He sees himself too, and increasingly so as events turn against him, still 
as slight, vulnerable. This is the real self to which he has been chosen. His striving for comfort out of these depths seems reduced to a form.

I can't claim to be satisfied with the conclusion to the poem. Müntzer having failed, and seen his visions evaporate, struggles to articulate some meaning for his life. Always uneasy about what is real and what fantastic, he has driven through his doubt, accepted the "very clear things" as true, culminating in the rainbow at Frankenhausen. But now what does he believe? Shrivelling that grandiose selfhood he fuses the Christian idea of eternal life with a notion of the determined fulfillment of history and of progress. It is meant as a measured but also forced and iron assertion, determined at least to triumph over doubt. He may be right.

My own major reservation about the poem concerns the deliberation of pattern, imagery, and theme which Rodney Pybus so sensitively picks out. I am worried that such a method of writing a poem responds too closely to evolved modes of literary criticism and that the poem as a result is too enclosed within its own genre. Ideally I should want (ambitiously) the poem to be some addition to our knowledge, and I believe that it is possible to speak meaningfully about history and politics in non-discursive ways. But the genre provides its own definitions and interests and so awards itself valueless self-sufficiency. I find it impossible not to feel this self-enclosure of the poem now as a constraint.

\section{Anne Frank's House / Rodney Pybus}

I seem to be

Anne Frank

transparent

as a branch in April.

-Yevtushenko, Babi Yar

Pushing aside sallow lace curtains, I can see the clock-tower and the bulbous West Church spire loom over the burgers' roof-tops on Prinzengracht. A chestnut tree coppers the wet November grass, forging this courtyard's unchanging backwater elegance.

Not difficult to imagine in this annex, now sealed off for thirty years from the hustle of the seasons, a girl's sense of muffled security, far from the strident rhythm of boots on cobbles, the firecracker racket of small-arms, 